\title{
Impact of Market Segmentation Strategies on Customer Loyalty: The Mediating Role of Positioning Effectiveness of Interior Design Industries within the Kumasi Metropolis
}

\author{
Alfred Owusu, Gertrude Agyemang \\ Department of Marketing, School of Business, Kumasi Technical University, Kumasi, Ghana \\ Email address: \\ alfredowusu020@gmail.com (A. Owusu), trudygertrude92@gmail.com (G. Agyemang) \\ To cite this article: \\ Alfred Owusu, Gertrude Agyemang. Impact of Market Segmentation Strategies on Customer Loyalty: The Mediating Role of Positioning \\ Effectiveness of Interior Design Industries within the Kumasi Metropolis. European Business \& Management. Vol. 7, No. 1, 2021 , pp. 1-13. \\ doi: $10.11648 /$ j.ebm.20210701.12
}

Received: November 17, 2020; Accepted: December 4, 2020; Published: January 22, 2021

\begin{abstract}
The buying behaviour of potential customers in terms of interior designs in Ghana differs from those in the Western context. There is a relatively low patronage of interior design products or services compared to the Western context (Ogunduyile et al, 2008). Existing literature have often looked at the direct causal relationship between market segmentation strategies and customer loyalty without emphasizing the effectiveness of positioning which could drive customer loyalty (Yim et al., 1999). The paper focuses on assessing the impact of market segmentation strategies on customer loyalty of Interior Design Industries, with the mediating role of positioning effectiveness. A total of 220 customers of Interior Design Industries within the Kumasi Metropolis of which 200 responses were obtained representing 90\% response rate. Convenience sampling techniques was used in selecting customer's whiles Structural Equation Model was used to analyze the data. The study revealed that, Behavioural, psychographic and demographic segmentations impacted positively on customer loyalty. Geographic segmentation variable however, impacted negatively on customer loyalty. Psychographic segmentation impacted positively on positioning effectiveness and customer loyalty. Positioning Effectiveness partially mediates between psychographic segmentation strategies and customer loyalty. Positioning Effectiveness has no mediation between geographic segmentation, behavioural segmentation, demographic segmentation and customer loyalty.
\end{abstract}

Keywords: Interior Design Industries, Market Segmentation Strategies, Psychographic Segmentation, Positioning Effectiveness, Customer Loyalty

\section{Introduction}

Market segmentation strategies and its impact on customer relationship have been widely studied to confirm a positive outcome by marketing researchers. The segmentation strategy must be entirely precise in order for a business to effectively target its desired group [29] and if businesses have market segment well - described and pervaded, the business will get a stronger market position [28]. However, successfully dividing a market can be a challenging activity. Customers work on multiple levels and it is difficult to comprehend how and on what customers do. Unfortunately, individual demand that causes distinct businesses to come to distinct conclusions is not immediately apparent. This is because of variations in their theoretical and analytical strategy as to which segment is correct. It is also noted that segmentation depends entirely on all four traditional bases, not one [12]. This facilitates that in order to find the dominant basis for market segmentation, further study is needed in the field of market segmentation in separate specific fields.

Previous studies also concentrated on the impact market segmentation has on customer satisfaction to the neglect of customer loyalty $[22,26,11]$. It must be noted, however, it is a fallacy to assume customers are loyal just because they continue to purchase from the company. There are many reasons why customers repeat purchasing which may have little to do with being loyal. Behavioral loyalty evaluation has been reigning for years and continues to play a significant impact in both the operationalization of brand 
loyalty and customer loyalty $[10,21]$. A vast majority of customer loyalty behavioural measures depend on their basis of repurchase conduct. A certain level of abstraction is essential to correctly describe customer loyalty. Some level of abstraction is needed to correctly describe customer loyalty conceptually. Definitions of concept form the basis of formal theory [10]. Customer loyalty can, at most, only be anticipated without a conceptual definition. Researchers would never hope to understand how customer loyalty can be improved, modified or diagnosed. Finally, only now are scales that are valid and reliable suggested, which measure the loyalty of customers but these are proved inadequate [21].

Additionally, review of literature on market segmentation strategies and its impact on customer loyalty and positioning effectiveness mostly focused on other industries such as the banking industry to the neglect of interior design industry. Although, there has been an increase in knowledge of the importance of interior design, some potential customers in Africa particularly Ghana have not fully appreciated the importance of interior designs. Most potential customers do not see the need to invest so much into interior designs as they view it not a necessity but as a waste of money and as luxurious products or services. Moreover, the buying behaviour of potential customers in terms of interior designs differs from those in the Western context. There is a relatively low patronage of interior design products or services compared to the Western context [24]. Existing literature have often looked at the direct causal relationship between market segmentation strategies and customer loyalty without emphasizing the effectiveness of positioning which could drive customer loyalty [34].

This therefore called for an urgent concern about market segmentation strategies by gaining customer loyalty through positioning effectiveness, a subject which had not received the needed attention. Positioning, in the field of marketing studies, is essential but limited in research. In positioning research, marketers have created an impressive range of extremely useful research methods and models. Research on positioning effectiveness on the conceptual and empirical front, however, is scarce and lags behind. The outcome of an effective positioning strategy is the creation of a successful value proposition concentrated on the customer, a clear and convincing explanation of why a target market should purchase the market offering. [16]. Taking these arguments together, it can be deduced that in determining customer loyalty, positioning effectiveness through the customer's lens is considered to be a more conceptually sound strategy. [33] advocates that positioning can be examined by evaluating customers' or organizational buyers' perceptions and preference for the product or service in relation to competition. Positioning effectiveness can only be accomplished by taking a customer view and understanding how brands in the product category are perceived by customers [31]. Therefore, this research sought to assess the impact of market segmentation strategies on customer loyalty with positioning effectiveness as the mediating role. This research mainly seeks to determine the impact of market segmentation strategies on customer loyalty, the mediating role of positioning effectiveness within Kumasi Metropolis.

\section{Literature Review}

\subsection{Theoretical Framework and Hypothesis Development}

Competitive Advantage Theory as stipulated by Michael Porter in 1985 states that a firm gains competitive advantage when its attributes or resources allows a firm to outperform its competitors. The foundations on which a company can strive to attain a permanent position in its setting are known as Generic Strategies. These are the basic ways in which companies can gain a sustainable competitive advantage as established by Michael Porter. These are Focus strategy, Differentiation strategy and Cost Leadership strategy. In relation to the study, the focus strategy and differentiation strategy is taken into consideration as it is applicable to the hypothesis development (Porter, 1985).

The focus strategy concentrates on a selected few target markets. It is also called a niche strategy. These niches could be a specific customer group, a small product line segment, a regional or geographical market, or a niche with unique tastes and preferences. The fundamental concept behind the focus strategy is to specialize the operations of the company in ways that wide - ranged or cheap companies are unable to do in any other better way. By concentrating on one or two small market segments and customizing the marketing mix to these specific markets, a company can better fulfil its target market requirements [27]. Companies using the focus strategy concentrates on a particular niche market in order to comprehend the market's dynamics and the distinctive needs of its customers as well as create a distinguished low - cost or accurate market offerings for its customers.

Companies that use the focus strategy serve customers uniquely well in their industry and tend to gain an irresistible loyalty from its customers [6]. This is applicable to the study because when a firm selects a particular segment to serve, superior value and greater profitability are produced when other companies operating at a broader - line are unable to specialize or carry out their operations better than a company that is concentrated or focused.

Differentiation strategies assumes delivering customers something that distinguishes a company's offerings from competition which makes it more appealing (Porter, 1985). The primary reason behind a differentiation strategy is that customers are prepared to settle up a greater cost for a unique market offering. How a firm achieves this, depends on the exact nature of the industry, the market offering and usually involves features, functionality, durability, support and also the image of the brand that customer's value. Superior value is developed because the product or service is of greater quality, is in some manner technically superior, or in some perceived manner has a unique attraction. In fact, the differentiation approach creates a competitive advantage by making customers loyal and less price - sensitive to a specific company's offering. [3]. Therefore, Competitive 
Advantage theory explains the role market segmentation strategies and positioning effectiveness play in the Generic Strategies stipulated by Michael Porter in 1985.

Segmentation based on geographic, divides customers across continents, nations, areas, counties or neighborhoods. Geographic segmentation provides a platform to get a general opinion of how things work in a specific area. Segmenting customers in this way can be beneficial because it provides a brief analysis of the differences between the customers depending on where they are located, the possibility to determine differences in culture, ability to acknowledge the differences in climate and language. [20]. Geographic segmentation is a shared approach that is applied when a firm seeks to serve its customers in a specific setting or when its target market has distinct preferences depending on the location and exceeds the customer's expectations.

Through geographic segmentation, firms offer different marketing messages to different customers based on their preferences and tastes which in turn, enables them to understand location-based attributes of a specific target market. Additionally, geographic segmentation allows firms to know its customers well and therefore offers a more personal value proposition that addresses the needs and wants of its customers' location specifically. In line with the focus strategy as established by Porter in 1985, a firm may seek to gain customer loyalty by allocating its resources to produce a market offering that meets the needs and wants of a particular segment geographically. Thus, a firm differentiates itself when it adheres to the differences of its customers based on location hence occupies a unique place in the minds of its customers [17]. Hence, it can be deduced that:

a) Positioning Effectiveness positively mediates the relationship between Geographic Segmentation and Customer Loyalty

Behavioural Segmentation, Positioning Effectiveness and Customer Loyalty

Behavioural segmentation is a more concentrated aspect of market segmentation strategy that divides customers based on particular patterns of behaviour exhibited during buying decisions, enabling marketers to tailor their marketing strategy to particular markets in order to attain the loyalty of its customers. This can be done through good relationship and communication with the customer and well-known patterns and habits of the customers [20] as stipulated in the focus strategy (Porter, 1985).

The product or service requires to be efficiently placed in the minds of customers to guarantee market recognition. [8]. Behaviour segmentation enables firms to have excellent record keeping of customers and their purchases. Firms are able to point out customers who have bought certain types of products or services and what they may have spent at certain levels and in that way, develop a positioning strategy that provides special offers. Firms that are thorough and have kept good records of its customers would have a good understanding of the buying patterns and behaviour of its customers thus position their products or services effectively to gain competitive advantage leading to customers' acceptance of the products or services and their willingness to continue to do business with such a firm [17]. This study hypothesizes that:

b) Positioning Effectiveness positively mediates the relationship between Behavioural Segmentation and Customer Loyalty

Psychographic Segmentation, Positioning Effectiveness and Customer Loyalty

Firms segment their customers according to psychographics to mainly understand why customers would want to purchase a firm's product or service. Psychographic segmentation divides customers in to factors such as attitude, lifestyle and beliefs. Psychographic segmentation influences the way firms market their offerings to give customers an appearance or appeal that attracts them [32]. Segmenting customers based on psychographic variable, favors firms by giving them knowledge in knowing why customers buy specific products or services, it gives the firms the ability to tailor its way to market the offering to the customer's personal traits [15].

Customers in a group may exhibit differences in psychographic features. With psychographic segmentation, firms are able to distinguish customers who are timeconstrained or money-constrained thus, an effective positioning strategy enables firms to align its market offerings to suit the requires and desires of its customers according to their respective lifestyles in a unique way better than its competitors as established by Porter (1985) in the differentiation strategy. Hence:

c) Positioning Effectiveness positively mediates the relationship between Psychographic Segmentation and Customer Loyalty

\subsection{Geographic Segmentation, Positioning Effectiveness and Customer Loyalty}

Segmentation based on geographic, divides customers across continents, nations, areas, counties or neighborhoods. Geographic segmentation provides a platform to get a general opinion of how things work in a specific area. Segmenting customers in this way can be beneficial because it provides a brief analysis of the differences between the customers depending on where they are located, the possibility to determine differences in culture, ability to acknowledge the differences in climate and language. (McDonald \& Dunbar, 2012). Geographic segmentation is a shared approach that is applied when a firm seeks to serve its customers in a specific setting or when its target market has distinct preferences depending on the location and exceeds the customer's expectations.

Through geographic segmentation, firms offer different marketing messages to different customers based on their preferences and tastes which in turn, enables them to understand location-based attributes of a specific target market. Additionally, geographic segmentation allows firms to know its customers well and therefore offers a more personal value proposition that addresses the needs and wants of its customers' location specifically. In line with the focus 
strategy as established by Porter in 1985, a firm may seek to gain customer loyalty by allocating its resources to produce a market offering that meets the needs and wants of a particular segment geographically. Thus, a firm differentiates itself when its adheres to the differences of its customers based on location hence occupies a unique place in the minds of its customers (Kotler et al., 2003). Hence, it can be deduced that:

a) Positioning Effectiveness positively mediates the relationship between Geographic Segmentation and Customer Loyalty 2012).

\subsection{Behavioural Segmentation, Positioning Effectiveness and Customer Loyalty}

Behavioural segmentation is a more concentrated aspect of market segmentation strategy that divides customers based on particular patterns of behaviour exhibited during buying decisions, enabling marketers to tailor their marketing strategy to particular markets in order to attain the loyalty of its customers. This can be done through good relationship and communication with the customer and well-known patterns and habits of the customers (McDonald \& Dunbar, 2012) as stipulated in the focus strategy (Porter, 1985).

The product or service requires to be efficiently placed in the minds of customers to guarantee market recognition. (Guiltinan, 1999; Ottum, 1996). Behaviour segmentation enables firms to have excellent record keeping of customers and their purchases. Firms are able to point out customers who have bought certain types of products or services and what they may have spent at certain levels and in that way, develop a positioning strategy that provides special offers. Firms that are thorough and have kept good records of its customers would have a good understanding of the buying patterns and behaviour of its customers thus position their products or services effectively to gain competitive advantage leading to customers' acceptance of the products or services and their willingness to continue to do business with such a firm (Kotler et al., 2003). This study hypothesizes that:

b) Positioning Effectiveness positively mediates the relationship between Behavioural Segmentation and Customer Loyalty

\subsection{Psychographic Segmentation, Positioning Effectiveness and Customer Loyalty}

Firms segment their customers according to psychographics to mainly understand why customers would want to purchase a firm's product or service. Psychographic segmentation divides customers in to factors such as attitude, lifestyle and beliefs. Psychographic segmentation influences the way firms market their offerings to give customers an appearance or appeal that attracts them (Wedel \& Kamakura, 1999). Segmenting customers based on psychographic variable, favors firms by giving them knowledge in knowing why customers buy specific products or services, it gives the firms the ability to tailor its way to market the offering to the customer's personal traits (Kotler et al., 2000).
Customers in a group may exhibit differences in psychographic features. With psychographic segmentation, firms are able to distinguish customers who are timeconstrained or money-constrained thus, an effective positioning strategy enables firms to align its market offerings to suit the requires and desires of its customers according to their respective lifestyles in a unique way better than its competitors as established by Porter (1985) in the differentiation strategy. Hence:

c) Positioning Effectiveness positively mediates the relationship between Psychographic Segmentation and Customer Loyalty

\subsection{Demographic Segmentation, Positioning Effectiveness and Customer Loyalty}

Firms that segment its customers according to demographics categorize them according to age, gender, religion, income, size of family, education and occupation (McDonald \& Dunbar, 2012). Demographic segmentation allows customers to identify themselves with a firm's product or service and makes the firm an advocate for their needs and wants, which in turn makes customers more likely to do business with such a firm over a long period (Kotler, 2000). When a firm identifies the demographics of its customers, it becomes easier to choose which customers to accommodate in terms of its market offerings and how uniquely the offerings can overly delight its customers, thus the ability to meet their needs and wants. In today's business environment, competition is highly driven hence the need to identify its customers' makeup and producing products or services that match the demographics of customers as well as occupying a distinctive place in the minds effectively by the result of an excellent marketing strategy which generates the loyalty of customers (Kotler et al., 2005). Demographic segmentation enables firms to have a deeper understanding of its customers' makeup and create its positioning strategy effectively so as it suits the preferences and tastes of customers to gain loyalty (Kotler et al, 2005). Thus it can be deduced that:

d) Positioning Effectiveness positively mediates the relationship between Demographic Segmentation and Customer Loyalty

\section{Geographic Segmentation, Positioning Effectiveness and Customer Loyalty}

\subsection{Demographic Segmentation, Positioning Effectiveness}

Firms that segment its customers according to demographics categorize them according to age, gender, religion, income, size of family, education and occupation [20]. Demographic segmentation allows customers to identify themselves with a firm's product or service and makes the firm an advocate for their needs and wants, which in turn makes customers more likely to do business with such a firm over a long period [15]. When a firm identifies the demographics of its customers, it becomes easier to choose 
which customers to accommodate in terms of its market offerings and how uniquely the offerings can overly delight its customers, thus the ability to meet their needs and wants. In today's business environment, competition is highly driven hence the need to identify its customers' makeup and producing products or services that match the demographics of customers as well as occupying a distinctive place in the minds effectively by the result of an excellent marketing strategy which generates the loyalty of customers [14]. Demographic segmentation enables firms to have a deeper understanding of its customers' makeup and create its positioning strategy effectively so as it suits the preferences and tastes of customers to gain loyalty [14]. Thus it can be deduced that:

d) Positioning Effectiveness positively mediates the relationship between Demographic Segmentation and Customer Loyalty

\subsection{Overview of Interior Design Industry}

Interior design is a multi - faceted profession where creative and technical alternatives are applied to a built-in interior setting within a building. These alternatives are functional and improve the occupants' quality of life and culture [23]. The interior design industries in Ghana have gone through a number of evolutionary changes. The days have gone by when it was assumed that interior designs were a splendorous expression for sensitivity and excellent taste in room decoration. As time changes, there are customers who realize the true necessity of having a space taken care of by specialist, alongside an overview of comfortability and pleasure for all. Interior design is a method that offers a number of aesthetically pleasing but effective alternatives for optimal use of the room in question to its customers. The objective of interior design is to enhance the customer experience by better handling the environment space available. There are several difficulties that make interior design a field-based activity created by experts. Basically, it is a way of transforming the lives of individuals living or enjoying a certain room, enhancing their quality of life by designing and decorating it. [23]

Some customers are beginning to seek experts' advice in their homes; to create a relaxing and conducive environment for retreat after a long day. There has also been a desire for differentiation of space and homes. Additionally, some customers are now expectant of the serenity in restaurants in terms of physical evidence which captures the ambience of the place. Interior designs have also become a necessity in hospitals whereby doctors and nurses need environment that help them focus on information and work accurately. Patients in their rooms need to feel comfortable and relaxed, shortening the healing time. Hence, through the effectiveness of positioning strategies implemented by interior design industries, customer would then become loyal.

Interior design industries therefore must not only seek to segment its market in order to retain customers but must ensure that there is an effective positioning strategy that seeks to create a clean, differentiated, sophisticated and peaceful environment for its customers in order to gain their loyalty.

\section{Methodology}

Descriptive research design was utilized to assess the impact of market segmentation strategies on customer loyalty; explanatory research design was also used to determine positioning effectiveness as the mediating role between market segmentation strategies and customer loyalty. Quantitative research method was employed by the researcher for the purpose of analyzing the data. The study population consisted of Interior Design Industries in Ghana but the study focused on those in the Kumasi Metropolis of Ghana.

In achieving the research objectives, the analytical unit were the customers of the target interior design industry. The population comprised target customers of interior design industry in the Kumasi Metropolis, due to the unstructured nature and little knowledge in interior design database; it is difficult to determine the actual population of customers in the industry. 220 respondents were drawn from the target interior design industry. Due to the fact that the population was not known, the research employed the convenience sampling technique even though it deals more with the qualitative approach. The respondents were reached from their homes, offices, hotels, hospitals and at the shop where the target interior design industry is situated; the respondents were willing and available to state their opinions with respect to the research.

Primary data sources were employed solely through the use of questionnaires. The questionnaire was divided into three sections namely; Market Segmentation Strategies, Customer Loyalty and Positioning effectiveness with each section measuring a specific variable as elaborated as follows: Section A was purposely used to gather as well as measure data in relation to the independent variable of Market Segmentation Strategies. This section was further subdivided into four dimensions whereby each dimension measured Market Segmentation Strategies. Thus, Market Segmentation was conceptualized and operationalized as multi dimensional construct; the dimensions were Geographic Segmentation, Behavioural Segmentation, Psychographic Segmentation and Demographic Segmentation. However, Demographic Segmentation was put at the last page of the questionnaire because it was observed that respondents were unwilling to provide their personal details at the start of a questionnaire but prefer that it was the last portion.

The number of questions under this section were 19 in all. The items used to measure geographic segmentation; behavioural segmentation, psychographic segmentation and demographic segmentation were three, five, six and five respectively. A 5-point Likert scale varying from $1=$ strongly disagree to $5=$ strongly agree for the subsection of geographic segmentation, behavioural segmentation and psychographic segmentation was used. Respondents were requested to give their opinion on the various market segmentation strategies, 
to what extent they agree with the statement or disagree. Additionally, categorical questions such as gender, age, marital status, and educational level and income levels were used in the demographic section. Section B was sought to purposely gather and measure data on the dependent variable of Customer Loyalty.

Customer Loyalty was conceptualized and operationalized as one-dimensional construct. The items used to measure customer loyalty were six using a 5-point Likert scale ranging from $1=$ Strongly disagree to $5=$ Strongly agree. Respondents were asked to provide their stance on customer loyalty, the extent to which they agree with the statement or disagree. Section $\mathrm{C}$ also sought to purposely gather and measure data on the mediating variable of Positioning Effectiveness. Positioning Effectiveness was conceptualized and operationalized as one-dimensional construct. The items used to measure positioning effectiveness were five using a 5 -point Likert scale varying from $1=$ Strongly disagree to $5=$ Strongly agree. Respondent were requested to indicate what comes to mind in relation to interior design industry, by stating to what extent they strongly agree or disagree to the statement provided.

Reliability and validity were tested through the use of LISREL (8.50) to critically assess the scales using Confirmatory Factor Analysis (CFA) which allowed to test the hypotheses understudy thus, CFA asses that the measured variable measures the exact number of constructs. Coherently, any item not suitable for the measurement model owing to low factor loading should be removed from the model therefore the researcher employed CFA to remove any measurement construct that resulted as poor indicators. The factor loadings of each construct to their latent variable were above the threshold of 0.5 . Moreover, each construct loaded under their respective latent variables which exhibited convergence and discriminant. Recommendations for a good construct was also assessed with regards to the model fit indices which were Chi Square / Degree of Freedom ( $\left.x^{2} / d f\right)$, Root of Mean Square Error of Approximation (RMSEA), Non -Normed Fit Index (NNFI), Comparative Fit Index (CFI) and Standardized Root Mean Square Residual (SRMR). All the model fit indices had a cut - off point to prove its fitness of the respective model.

The cutoff - point for Chi Square / Degree of Freedom $\left(\mathrm{x}^{2} /\right.$ df) must be less or equal to 2. Recommendations for cut off point for Root of Mean Square Error of Approximation (RMSEA) were significantly decreased in the last fifteen years, until the early 90 s the RMSEA between 0.05 and 0.10 was considered to be a fair fit and values above 0.10 indicated poor fit [18]. Also, it was thought that RMSEA between 0.08 to 0.10 provided a mediocre fit whereas below 0.08 showed a good fit [18]. Recently, a cut-off point of 0.06 or an upper limit of 0.07 seems to be the general consensus [9], [30]. Recommendation from [9] suggested a cut off point for Non-Normed Fit Index (NNFI) to be greater or equal to 0.90, a cut off criterion for Comparative Fit Index (CFI) should be greater or equal to 0.90 , nevertheless recent studies have proven that a value that is greater than 0.90 is much useful to ensure that non specified models are not accepted [9].

\section{Results}

\subsection{Reliability and Validity}

Testing for the reliability and validity of the measures, LISREL (8.50) was used to check all scales in the Confirmatory Factor Analysis (CFA). The CFA was used to point out any problematic indicators of the constructs. Tables utilized were from 1 to 2 . The factor loadings, T- values, Cronbach Alpha (CA), Average Variance Expected (AVE), Composite Reliability (CR), convergence and discriminant with the respective fit indices for the variables under study were all taken into consideration and checked for.

Market Segmentation was measured using lower dimensions which were Geographic Segmentation, Behavioural Segmentation, Psychographic Segmentation and Demographic Segmentation. Moreover, the other variables used for this study was Positioning Effectiveness and Customer Loyalty which were both measured as uni dimensional variables. The lower dimensions of Market Segmentation Strategies were measured with a construct of three, five and six respectively. Customer Loyalty and Positioning Effectiveness were also measured with a lower dimension construct which were six and five respectively. Many items were taken out from the model after purification, Table 1 shows the final list of items, their respective standardized factor loadings and $\mathrm{T}-$ values and results of reliability and validity test. According [1], the loadings and the $\mathrm{T}$-values of the variables under study should be greater or equal to $(\geq) \quad 0.5$ and greater or equal to $(\geq) 1.95$ respectively. The results display the Cronbach Alpha, Composite Reliability and discriminant validity of the variables are acceptable [1]. The Average Variance Expected were larger than the shared variances between constructs, Additionally, the construct loadings and the T-values were all greater than the threshold hence making the constructs good for further analysis. From Table 1. Refer appendix 2 the, the positive and significant loadings confirm convergent validity of the measures indicating satisfactory discriminant validity [7].

For a good fit model, the general requirement is that Chi Square/ Degree of Freedom $\left(\mathrm{x}^{2} / \mathrm{df}\right)$ should be less or equal $(\leq)$ to 2 Root of Mean Square Error of Approximation (RMSEA) should be less or equal $(\leq)$ to 0.07 , (Non -Normed Fit Index (NNFI) should be greater or equal $(\geq)$ to 0.90 , Comparative Fit Index (CFI) should be greater or equal $(\geq)$ to 0.90 and Standardized Root Mean Square Residual (SRMR) should be less or equal $(\leq)$ to $0.07[1,5]$. From the analysis, Chi Square/ Degree of Freedom was exactly 2, RMSEA was exactly 0.07 , NNFI was exactly 0.90 , CFI was 0.91 and SRMR was 0.059 ; therefore, all indices were all fit and satisfactory for further analysis.

\subsection{Correlation Matrix}

Correlation shows the relationship between variables of 
interest. The strength of the relationship can be determined by the Pearson correlation ( $r$ ). If the $r$ value is 0 , then no relationship between two variables is indicated and if the $r$ value is 1 , then it can be interpreted as a true positive correlation, whereas if the $r$ value is -1 , it can be interpreted as negative correlation. Based on the research of [4], the $r$ value can indicate the strength of the relationship. Correlation measures the strength or extent of an association between the variables and also its direction as seen in Table 3 .

Table 3, presents the correlations between the variables of interest. The results show that there is a weak strength relationship between geographic segmentation and customer loyalty and a negative correlation $(\mathrm{r}=-0.139, \mathrm{p}<0.05)$. The correlation analysis shows that geographic segmentation has a significant but negative relationship with customer loyalty. There is a medium strength relationship between behavioural segmentation and customer loyalty and a positive correlation $(\mathrm{r}=0.339, \mathrm{p}<0.01)$. The correlation analysis shows that behavioural segmentation has a significant and positive relationship with customer loyalty. Psychographic segmentation and customer loyalty shows a medium strength relationship and a positive correlation $(\mathrm{r}=0.420, \mathrm{p}<0.01)$.

For the relationship between demographic segmentation and customer loyalty, it shows a weak strength relationship and a positive correlation $(\mathrm{r}=0.241, \mathrm{p}<0.01)$. The results show no strength of relationship between geographic segmentation and positioning effectiveness and a positive correlation $(\mathrm{r}=0.064)$ and it is insignificant. The correlation analysis shows that geographic segmentation does not significantly relate with positioning effectiveness. There is a weak strength of relationship between behavioural segmentation and positioning effectiveness and positive correlation $(\mathrm{r}=0.134)$. Psychographic segmentation and positioning effectiveness show a positive but weak relationship $(\mathrm{r}=0.297, \mathrm{p}<0.01)$. The correlation analysis shows no strength of relationship between demographic segmentation and positioning effectiveness $(\mathrm{r}=0.088)$ and it is insignificant. Lastly, the correlation analysis shows the relationship between positioning effectiveness and customer loyalty. From the results, there is a strong and positive relationship between positioning effectiveness and customer loyalty $(\mathrm{r}=.544, \mathrm{p}<0.01)$.

\subsection{Analyzing Hypotheses}

The Table 4 above shows the estimates, t-values and other model indices. Model 1 specify that market segmentation strategies accounted for $26.4 \%$ shared variance on customer loyalty. The study hypothesized for the relationship between market segmentation strategies (Geographic Segmentation, Behavioural Segmentation, Psychographic Segmentation and Demographic Segmentation) and customer loyalty of interior design industries. From model 1, it shows the direct effect on the market segmentation strategies (Geographic Segmentation, Behavioural Segmentation, Psychographic Segmentation and Demographic Segmentation) on customer loyalty. The results show that Behavioural Segmentation, Psychographic Segmentation and Demographic
Segmentation are statistically significant with $\beta=.135, .252 .195$, and $t$-values $=2.638,4.699$ and 2.484 respectively. However, Geographic Segmentation $\beta=-.091$ and $t$-value $=-2.967$, showing a negative impact on customer loyalty. Hence, when all things are held constant, if there is an increase in Geographic Segmentation, the loyalty of customers would decrease. Therefore, Geographic Segmentation is statistically insignificant.

Having checked the validity of the measurement constructs' suitable for statistical analysis, the structural equation modeling was employed to investigate the relationship between the variables. Specifically, to determine whether positioning effectiveness had any mediating role in the relationship between geographic segmentation, behavioural segmentation, psychographic segmentation, demographic segmentation and customer loyalty. Several techniques for testing hypotheses regarding mediation were suggested [91]. The frequently used method is the causal steps strategy, stipulated by [2] which estimates the paths of the model, using Ordinary Least Square (OLS) regression or SEM, which assess the degree of fulfilment of several criteria. [2] Suggested three significant but not adequate circumstances to allow mediation to be claimed. For mediation circumstances: The independent variable is substantially associated to the mediator; the mediator is substantially associated to the dependent variable. When the mediator is in the model, the relationship of the independent variable to the dependent variable decreases. It implies that each of the three constructs should show a nonzero monotonous link with each other, and the connection between the independent variable to dependent variable should reduce significantly when $M$ is added as a predictor of $\mathrm{Y}$ [13].

Model 4 from Table 4 shows the indirect effect of the mediating role of Positioning Effectiveness as a link between Market Segmentation Strategies (Geographic Segmentation, Behavioural Segmentation, Psychographic Segmentation and Demographic Segmentation) and Customer Loyalty. The results show that, the effect of Geographic Segmentation is negative when the mediator variable is introduced to the equation. With regards to the Path Estimation Model in Table 5 using the Sobel Test, the total effect for Geographic Segmentation is -.100 , the effect if the mediator variable (Positioning Effectiveness) is introduced between the independent variable (Geographic Segmentation) and dependent variable (Customer Loyalty) is negative. The direct effect for Geographic Segmentation is -.091 which is negative. The indirect effect of Geographic Segmentation that continues through Positioning Effectiveness is 0.01. The total effect of Geographic Segmentation on Customer Loyalty is not reduced after the introduction of Positioning Effectiveness. According to the proposition by [2] mediation did not occur, hence hypothesis $(a)$ is not supported.

Moreover, in Model 4 from Table 4, it can be seen that when Behavioural Segmentation passes through the mediator variable to the dependent variable of Customer Loyalty, the coefficient of the relation shows a positive impact of.141. Thus, Behavioural Segmentation is significantly related to 
Positioning Effectiveness and the mediator variable. With regards to the Path Estimation Model in Table 5 using the Sobel Test, the total effect for Behavioural Segmentation is 0.129 , the effect if the mediator variable (Positioning Effectiveness) is introduced between the independent variable (Behavioural Segmentation) and dependent variable (Customer Loyalty) is positive. The direct effect for Behavioural Segmentation is.135 which is positive. The indirect effect of Behavioural Segmentation, that continues through Positioning Effectiveness is -0.006 which is negative. The total effect of Behavioural Segmentation on Customer Loyalty is not reduced after the introduction of Positioning Effectiveness. Based on the premise by [2] mediation exists, hence hypothesis (b) is not supported.

When Psychographic Segmentation passes through the mediator variable to the dependent variable of Customer Loyalty in Model 4 from Table 4, the coefficient of the relation shows a positive impact of.149. Thus, Psychographic Segmentation is significantly related to Positioning Effectiveness and the mediator variable, Positioning Effectiveness, is significantly related to the dependent variable of Customer Loyalty. In reference to the Path Estimation Model in Table 5 using the Sobel Test, the total effect for Psychographic Segmentation is 0.374, the effect if the mediator variable (Positioning Effectiveness) is introduced between the independent variable (Psychographic Segmentation) and dependent variable (Customer Loyalty) is positive. The direct effect for Psychographic Segmentation is. 252 which is positive. The indirect effect of Psychographic Segmentation that continues through Positioning Effectiveness is 0.122 which is also positive. The total effect of Psychographic Segmentation on Customer Loyalty is reduced after the introduction of Positioning Effectiveness. Based on the postulation by [2] partial mediation exists, hence hypothesis (c) is supported.

From the Table 4 in Model 4, it can be deduced that when Demographic Segmentation passes through the mediator variable to the dependent variable of Customer Loyalty, the coefficient of the relation shows a positive impact of.165. Thus, Demographic Segmentation is significantly linked to Positioning Effectiveness and the mediator variable, Positioning Effectiveness, is significantly linked to the dependent variable of Customer Loyalty. In reference to the Path Estimation Model in Table 5 using the Sobel Test, the total effect for Demographic Segmentation is 0.23 , the effect if the mediator variable (Positioning Effectiveness) is introduced between the independent variable (Demographic Segmentation) and dependent variable (Customer Loyalty) is positive. The direct effect for Demographic Segmentation is. 195 which is positive. The indirect effect of Demographic Segmentation that continues through Positioning Effectiveness is 0.035 which is also positive. The total effect of Demographic Segmentation on Customer Loyalty is not reduced after the introduction of Positioning Effectiveness. Based on the stipulation by [2] mediation did not occur, hence, hypothesis $(d)$ is not supported.

\section{Discussion}

The research sought to assess the mediating role of positioning effectiveness in the relationship between market segmentation strategies and customer loyalty of Interior Design Industries within the Kumasi Metropolis, Ghana. Hence, the study sought to (a) assess the role of positioning effectiveness as a mediator between the relationship of geographic segmentation and customer loyalty, (b) determine the role of positioning effectiveness as a mediator between the relationship of behavioural segmentation and customer loyalty, (c) to analyze the role of positioning effectiveness as a mediator between the relationship of psychographic segmentation and customer loyalty and (d) to examine the role of positioning effectiveness as a mediator between the relationship of demographic segmentation and customer loyalty. Consequently, with reference to study's objectives, these four hypotheses were analyzed.

In this study, four mediation situations were tested with positioning effectiveness as the mediation variable and the relationship between geographic segmentation, behavioural segmentation, psychographic segmentation, demographic segmentation and customer loyalty as the direct effect. Hypothesis (a) stipulates that positioning effectiveness mediates the relationship between geographic segmentation and customer loyalty. In testing the mediation of positioning effectiveness, the direct effect of geographic segmentation on customer loyalty of Interior Design Industries within the Kumasi Metropolis was explored and the result was negative and statistically insignificant which implies that an increase in Interior Design Industries to segment its market geographically does not necessarily increase the loyalty of its customers. This does not support the study of [20]. Although, there exists negative relationship between geographic segmentation and customer loyalty, the study stipulated for positioning effectiveness as a mechanism through which geographic segmentation can improve customer loyalty. Thus, the mediating role of positioning effectiveness was tested in the relationship between geographic segmentation and customer loyalty and the result did not confirm the hypothesis, hence there was no mediation. Hence, when Interior Design Industries within the Kumasi Metropolis segment its market according to climate patterns, population density (urban, rural or suburban) or regions in order to offer its interior designs usually do not retain the loyalty of its customer since it is usually seen as a one-off transaction and not repeatedly overtime.

Additionally, hypothesis (b) argues that positioning effectiveness mediates the relationship between behavioural segmentation and customer loyalty of Interior Design Industries within the Kumasi Metropolis. Initially, the study tested the direct effect of behavioural segmentation and customer loyalty and the result was positive and significant which implies that an increase in behavioural segmentation is likely to increase customer loyalty. This is in line with the research of [20,32]. Although the direct effect of behavioural segmentation on customer loyalty was positive, the study 
stipulated for positioning effectiveness as a mediator through which the loyalty of customers can be enhanced. Hence, the mediating role of positioning effectiveness between behavioural segmentation and customer loyalty was assessed. However, the result show that the mediating role of positioning effectiveness between behavioural segmentation and customer loyalty although positive accounted for no mediation. The implication is that behavioural segmentation passing through positioning effectiveness does not play an important role in the improvement of customer loyalty as far as it is concerned with behavioural segmentation.

Hypothesis (c) argues that that positioning effectiveness mediates the relationship between psychographic segmentation and customer loyalty of Interior Design Industries within the Kumasi Metropolis. Firstly, the study confirmed a positive and significant relationship between psychographic segmentation and customer loyalty of Interior Design Industries within the Kumasi Metropolis, implying that an increase in psychographic segmentation is likely to increase the loyalty of customers. This is in line with the research of [32]. To further assess, the direct effect of psychographic segmentation on customer loyalty was positive, the study stipulated for positioning effectiveness as a mediator through which the loyalty of customers can be enhanced. Hence, the mediating role of positioning effectiveness between psychographic segmentation and customer loyalty was assessed. The result confirm that positioning effectiveness partially mediates the relationship between psychographic segmentation and customer loyalty. Thus, positioning effectiveness can serve as a mechanism through which psychographic segmentation can enhance the loyalty of customers of Interior Design Industries within the Kumasi Metropolis even though there is a direct positive of psychographic segmentation on customer loyalty, implying that an increase in psychographic segmentation is likely to increase the loyalty of customers of Interior Design Industries within the Kumasi Metropolis when the mediator, positioning effectiveness is introduced.

This proposes that the mediating role of positioning effectiveness together with other factors have a significant role on psychographic segmentation and which reflect in a better customer loyalty of Interior Design Industries within the Kumasi Metropolis. Therefore, of Interior Design Industries within the Kumasi Metropolis must ensure that its designs not only meet the lifestyle, personality and social status of its customers but must be positioned to be unique, superior and sophisticated in the minds of its customers effectively to ensure and retain the loyalty of its customers.

Lastly, the study evaluated hypothesis (d) positioning effectiveness mediates the relationship between demographic segmentation and customer loyalty of Interior Design Industries within the Kumasi Metropolis. Initially, the study tested the direct effect of demographic segmentation and customer loyalty and the result was positive and significant which implies that an increase in demographic segmentation is likely to increase customer loyalty. This is in line with the conclusion of [20]. Moreover, the mediating role of positioning effectiveness was introduced between demographic segmentation and customer loyalty although positive accounted for no mediation. The implication is that demographic segmentation passing through positioning effectiveness as it does not play a major role in how well customer loyalty of Interior Design Industries within the Kumasi Metropolis will increase when it comes to demographic segmentation.

\section{Conclusion}

The study demonstrates that when Behavioural Segmentation, Psychographic Segmentation and Demographic Segmentation is applied by Interior Design Industries, it will positively influence the level of loyalty from its customers. That is to say that, the higher Interior Design Industries employs Behavioural Segmentation, Psychographic Segmentation and Demographic Segmentation Strategies, the higher the possibility of increased loyalty from its customers. This is in conformity with literature that states that when firms involve in segmentation based on Behavioural Segmentation, Psychographic Segmentation and Demographic Segmentation Strategies, it will lead to customer loyalty [32], McDonald et al., 2002). It must be noted however that, Positioning Effectiveness only plays a critical role in Psychographic Segmentation in enhancing and impacting positively the loyalty of customers in Interior Design Industries within the Kumasi Metropolis.

\section{Recommendation}

Most potential customers do not see the need to invest so much into interior designs as they view it not a necessity but as a waste of money and as luxurious products or services [24]. Therefore, it is recommended that Interior Design Industries must segment its market based on psychographics alongside an effective positioning strategy that would go a long way to increase customer loyalty. The study found out that, positioning effectiveness plays a partial mediation role between psychographic segmentation and customer loyalty.

It is also recommended that, Interior Design Industries must not invest so much into Geographic, Demographic and Behavioural Segmentation Strategies as the study found out that positioning effectiveness does not play a mediation role. The implication is that, as far as Geographic, Demographic and Behavioural Segmentation Strategies are concerned; positioning effectiveness has no role to increase its customers loyalty. The market for Interior Design is not so intense within the Kumasi Metropolis, therefore the Interior Design Industry must strategize its market offering to suit the needs and wants of the psychographic segmented market.

\section{Contribution to Knowledge}

This research contributed both practical and theoretical to the concept of market segmentation strategies, positioning 
effectiveness and customer loyalty. The presence of psychographic segmentation on its own will positively impact customer loyalty of Interior Designs Industries within the Kumasi Metropolis. There is also another way that customer loyalty can be enhanced and it is through positioning effectiveness. As far as market segmentation strategies are concerned, positioning effectiveness plays a partial mediation role between psychographic segmentation and customer loyalty of Interior Designs Industries within the Kumasi Metropolis. Additionally, Interior Designs Industries can achieve success in attaining loyalty of its customers through behavioural and demographic segmentation even if they decide not to employ an effective positioning strategy as there is no mediation between behavioural segmentation and customer loyalty as well as demographic segmentation. Lastly, in the case of Geographic Segmentation, customers of Interior Designs Industries within the Kumasi Metropolis that are segmented geographically may not be necessarily loyal to
Interior Design Industries even with or without the mediating role of Positioning Effectiveness.

\section{Limitations}

Convenience sampling technique was used because the population is unknown although this study was a quantitative research. However, the researcher reduced research bias in such a way that the results obtained were not influenced to portray a certain outcome. The researcher found it difficult to analyse the demographic variables in segmentation with regards to gender, age, educational level, marital status and income levels. However, the use of dummy variables was utilized in data analysis. Respondents delayed in submitting the questionnaires administered, however, the researcher did remind the respondents through phone calls and agreed to collect the questionnaires on an agreed specified time.

\section{Appendix}

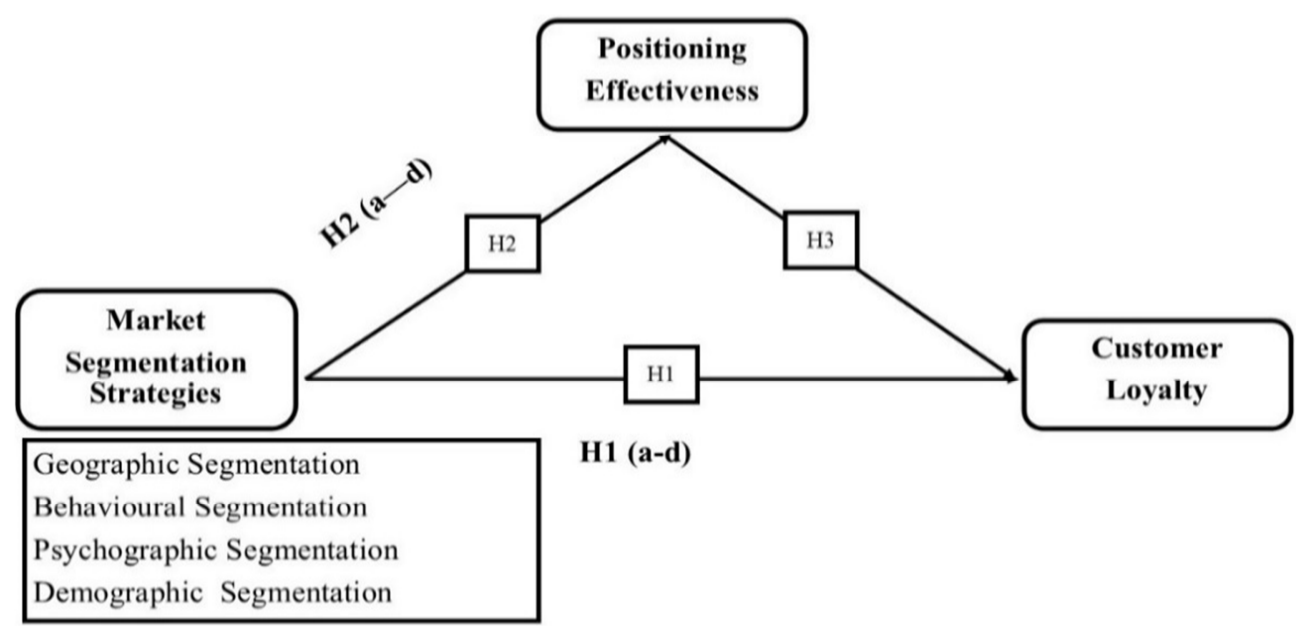

Source: Fieldwork, 2019

Figure 1. Conceptual Framework showing the relationship between Market Segmentation Strategies, Positioning Effectiveness and Customer Loyalty.

Table 1. Reliability and Validity Test.

\begin{tabular}{|c|c|c|c|}
\hline Measures & Loadings & T-values & B \\
\hline \multicolumn{4}{|c|}{ Geographic Segmentation $(\mathrm{CA}=0.865, \mathrm{CR}=0.867, \mathrm{AVE}=0.686)$} \\
\hline GS1 & The climate pattern influences my engagement in interior design & 0.76 & Fixed \\
\hline GS2 & The population density (urban, rural or suburban) affects my choice of interior design & 0.87 & 11.74 \\
\hline GS3 & The region determines the type of interior designs I opt for & 0.85 & 11.63 \\
\hline \multicolumn{4}{|c|}{ Behavioural Segmentation $(\mathrm{CA}=0.597, \mathrm{CR}=0.613, \mathrm{AVE}=0.349)$} \\
\hline BS1 & I change the interior designs of my environment often & 0.67 & Fixed \\
\hline BS2 & I prefer interior designs which suit my culture & 0.59 & 5.88 \\
\hline \multicolumn{4}{|c|}{ Psychographie Segmentation $(\mathrm{CA}=0.621, \mathrm{CR}=0.638, \mathrm{AVE}=0.380)$} \\
\hline PS1 & Interior Designs are one of the most important ways I have in expressing my individuality & 0.50 & Fixed \\
\hline PS3 & I spend a lot of money on Interior Design and accessories & 0.78 & 5.65 \\
\hline PS4 & I read interior design magazines or pay attention to interior design trends & 0.53 & 4.95 \\
\hline \multicolumn{4}{|c|}{ Customer Loyalty $(\mathrm{CA}=0.865, \mathrm{CR}=0.870, \mathrm{AVE}=0.529)$} \\
\hline CL1 & Overall, I am extremely satisfied with Interior Design industries & 0.71 & Fixed \\
\hline CL2 & I would highly recommend Interior Design industries to others & 0.71 & 9.33 \\
\hline CL5 & Over the past years, my loyalty to Interior design has grown stronger & 0.78 & 10.16 \\
\hline CL6 & Interior Design industries values people and relationships & 0.61 & 8.11 \\
\hline
\end{tabular}




\begin{tabular}{|c|c|c|c|}
\hline Measures & Loadings & T-values & B \\
\hline \multicolumn{4}{|c|}{ Positioning Effectiveness ( $\mathrm{CA}=0.686, \mathrm{CR}=0.730, \mathrm{AVE}=0.481$ ) } \\
\hline PE2 & Interior designs increases the value of a home & 0.59 & Fixed \\
\hline PE3 & Interior designers make a place attractive and pleasing aesthetically (beautifully) and functionally & 0.85 & 7.18 \\
\hline PE4 & Interior designers think outside the box to improve the outlook of a house or office & 0.61 & 6.55 \\
\hline
\end{tabular}

Notes: $\mathrm{CR}=$ construct reliability, $\mathrm{AVE}=$ average variance extracted, $\mathrm{CA}=\mathrm{Cronbach}$ 's alpha

Source: Fieldwork, 2019

Table 2. Confirmatory Factor Analysis (CFA) showing discriminant and convergence of the measures.

\begin{tabular}{|c|c|c|c|c|c|}
\hline \multirow{2}{*}{ Measures } & \multirow{2}{*}{\begin{tabular}{l|} 
Geographic \\
Segmentation \\
\end{tabular}} & \multirow{2}{*}{\begin{tabular}{l|} 
Behavioural \\
Segmentation \\
\end{tabular}} & \multirow{2}{*}{$\begin{array}{l}\text { Psychographic } \\
\text { Segmentation } \\
\end{array}$} & \multirow{2}{*}{\begin{tabular}{|l|} 
Customer \\
Loyalty \\
\end{tabular}} & \multirow{2}{*}{$\begin{array}{l}\text { Positioning } \\
\text { Effectiveness }\end{array}$} \\
\hline & & & & & \\
\hline GS1 & 0.76 & & & & \\
\hline GS2 & 0.87 & & & & \\
\hline GS3 & 0.85 & & & & \\
\hline BS1 & & 0.67 & & & \\
\hline BS2 & & 0.59 & & & \\
\hline BS3 & & 0.5 & & & \\
\hline PS1 & & & 0.5 & & \\
\hline PS3 & & & 0.78 & & \\
\hline PS4 & & & 0.53 & & \\
\hline CL1 & & & & 0.71 & \\
\hline CL2 & & & & 0.71 & \\
\hline CL3 & & & & 0.68 & \\
\hline CL4 & & & & 0.85 & \\
\hline CL5 & & & & 0.78 & \\
\hline CL6 & & & & 0.61 & \\
\hline PE2 & & & & & 0.59 \\
\hline PE3 & & & & & 0.85 \\
\hline PE4 & & & & & 0.61 \\
\hline
\end{tabular}

Source: Fieldwork, 2019

Table 3. Correlations.

\begin{tabular}{|c|c|c|c|c|c|c|}
\hline Variables & 1 & 2 & 3 & 4 & 5 & 6 \\
\hline 1. Geographic Segmentation & 1 & & & & & \\
\hline 2. Behavioural Segmentation & .120 & 1 & & & & \\
\hline 3. Psychographic Segmentation & .109 & $.474^{* *}$ & 1 & & & \\
\hline 4 Demographic Segmentation & -.079 & .128 & $.142^{*}$ & 1 & & \\
\hline 5. Customer loyalty & $-.139^{*}$ & $.339^{* *}$ & $.420^{* *}$ & $.241^{* *}$ & 1 & \\
\hline $\begin{array}{l}\text { 6. Positioning Effectiveness } \\
\text { *. Correlation is significant at the } 0.05 \text { level (2-tailed). } \\
\text { **. Correlation is significant at the } 0.01 \text { level (2-tailed). }\end{array}$ & .064 & .134 & $.297^{* *}$ & .088 & $.544^{* *}$ & 1 \\
\hline
\end{tabular}

Source: Fieldwork, 2019

Table 4. Regression Analysis.

\begin{tabular}{llllll}
\hline & \multicolumn{2}{l}{ Unstandardized estimates (t-values) } & & \\
\cline { 2 - 6 } & Model 1 & Model 2 & Model 3 & Model 4 & \multicolumn{1}{c}{ Significance } \\
\hline $\begin{array}{l}\text { Dependent Variables: } \\
\text { Independent Variables: Market Segmentation Strategies }\end{array}$ & Customer Loyalty & Positioning Effectiveness & Customer Loyalty & Customer Loyalty \\
Geographic Segmentation & $-.091(-2.967)$ & $0.19(.541)$ & & $-.100(-3.766)$ \\
Behavioural Segmentation & $.135(2.638)$ & $-.012(-.204)$ & & $.141(3.185)$ & .001 \\
Psychographic Segmentation & $.252(4.699)$ & $.232(3.757)$ & & $.149(3.111)$ & .000 \\
Demographic Segmentation & $.195(2.484)$ & $.066(.739)$ & & $.165(2.442)$ & .015 \\
Positioning Effectiveness & & & & $.446(8.310)$ & .000 \\
R & .514 & .303 & $.526(9.113)$ & .676 & .457 \\
$\mathrm{R}^{2}$ & .264 & .092 & .295 & .444 \\
Adjusted R Square & .249 & .073 & .292 & 5 \\
Df & 4 & 4 & 1 & 32.719 \\
F & 17.520 & 4.930 & 83.038 & .000 \\
Sig. & .000 & .001 & .000 & \\
\hline
\end{tabular}

Note: t-values are denoted in parentheses; Significance level at $\mathrm{p}<0.01$

Source: Fieldwork, 2019 
Table 5. Path Estimation Model.

\begin{tabular}{lllll}
\hline Path & Direct Effect & Indirect Effect & Total Effect & Sobel Test \\
\hline Geo P Effect Cus Loyal & -.091 & $.019 \times .526=0.01$ & -0.001 & 0.5417 \\
Behave P Effect Cus Loyal & .135 & $-.012 \times .526=-0.006$ & 0.129 & -0.2033 \\
Psych P EffectCus Loyal & .252 & $.232 \times .526=0.122$ & 0.374 & 3.4084 \\
Demo P Effect Cus Loyal & .195 & $.066 \times .526=0.035$ & 0.23 & 1.0016 \\
\hline
\end{tabular}

Source: Fieldwork, 2019

Notes: Geo=Geographic Segmentation; Behave=Behavioural Segmentation; Psych=Psychographic Segmentation; Demo=Demographic Segmentation; Cus Loyal=Customer Loyalty; P Effect=Positioning Effectiveness; Partial mediation significant $<0.05$.

\section{References}

[1] Bagozzi, R. P. and Y. Yi (2012). "Specification, evaluation, and interpretation of structural equation models." Academy of Marketing Science. Journal 40 (1): 8-34.

[2] Baron, R. M., \& Kenny, D. A. (1986). The moderatormediator variable distinction in social psychological research: Conceptual, strategic, and statistical considerations. Journal of Personality and Social Psychology, 51, 1173-1182.

[3] Bordes, J. (2009). Building and Sustaining Competitive Advantage. Atlantic International University Honolulu, Hawaii.

[4] Cohen, J. (1988). Statistical Power Analysis for the Behavioral Sciences (2nd ed.). Hillsdale, NJ: Lawrence Erlbaum Associates, Publishers.

[5] Fan, X., \& Sivo, S. A. (2005). Sensitivity of fit indices to misspecified structural or measurement model components: rationale of two index strategy revisited. Structural Equation Modeling, 12, 343-367.

[6] Fathali, A. 2016. "Examining the Impact of Competitive Strategies on Corporate Innovation: An Empirical Study in Automobile Industry," International Journal of Asian Social Science, Asian Economic and Social Society, vol. 6 (2), pages 135-145.

[7] Fornell, C., \& Larcker, D. F. (1981). Structural Equation Models with Unobservable Variables and Measurement Error: Algebra and Statistics. Journal of Marketing Research, 18, 382-388.

[8] Guiltinan, J. (1999), "Launch strategy, launch tactics, and demand outcomes", Journal of Product Innovation Management, Vol. 16 No. 4.

[9] Hu, L. T. \& Bentler, P. M. (1999), "Cutoff Criteria for Fit Indexes in Covariance Structure Analysis: Conventional Criteria Versus New Alternatives," Structural Equation Modeling, 6 (1), 1-55.

[10] Jacoby, J. \& Chestnut R. W. (1978). "Brand Loyalty, Measurement and Management". Journal of Advertising.

[11] Kabuoh M. N., Asikhia, Alagbe, A (2016) "Effect of Market Segmentation on Customer Satisfaction in Nigerian Banking Sector.” International Journal of Innovative Research in Social Sciences and Strategic Management Techniques.

[12] Kamineni, R., (2005), "The Next Stage of Psychographic Segmentation: Usage of Enneagram", Journal of American Academy of Business, Vol. 6, Issue 1, March, p 315-320.
[13] Kenny, D. A., Kashy, D. A., \& Bolger, N. (1998). Data analysis in social psychology. In D. Gilbert, S. T. Fiske, \& G. Lindzey (Eds.), Handbook of social psychology (4th ed., Vol. 1, pp. 233-265). New York: McGraw-Hill.

[14] Kotler, P. \& Keller, K. L. (2005) Marketing Management. 12th Edition, Prentice-Hall of India Private Limited, New Delhi.

[15] Kotler, P. (2000) Marketing Management. The Millennium Edition. Person Prentice Hall, Upper Saddle River.

[16] Kotler, P. and Armstrong, G. (2013) Principle of Marketing. 15th Edition, Prentice Hall.

[17] Kotler, P., \& Armstrong, G. (2003), Principles of Marketing, 10th ed., Prentice Hall of India: New Delhi, pp 320-325.

[18] MacCallum, R. C., Browne, M. W., \& Sugawara, H., M. (1996), "Power Analysis and Determination of Sample Size for Covariance Structure Modeling," Psychological Methods, 1 (2), 130-49.

[19] MacKinnon, D. P. (2000). Contrasts in multiple mediator models. In J. S. Rose, L. Chassin, C. C. Presson, \& S. J. Sherman (Eds.), Multivariate applications in substance use research: New methods for new questions (pp. 141-160). Mahwah, NJ: Erlbaum.

[20] McDonald, M. \& Dunbar, I. (2012). Market Segmentation: "How to do it, how to profit from it".

[21] McMullan, R. \& Gilmore, A. (2003). "The conceptual development of customer loyalty measurement: A proposed scale". Journal of Targeting, Measurement and Analysis for Marketing, 11 (3), 230-243.

[22] Mwenda, J. G \& Limiri, E. K. (2017) "Market Segmentation as a strategy for customer satisfaction and customer retention." International Journal of Economics, Commerce and Management.

[23] National Council for Interior Design Qualifications, (2004).

[24] Ogunduyile, S. R; Kayode, F. and Ojo, B. (2008). "Art and Design Practices in Nigeria: The Problem of Dropping Out". International Journal of Education \& the Arts.

[25] Ottum, B. D. (1996), "Launching a new consumer product", in Rosenau, M. D. Jr, Griffin, A Castellion, G. and Anschuetz, N. (Eds), The PDMA Handbook of New Product Development, Wiley, New York, NY.

[26] Premkanth, P. (2012) "Market Segmentation and Its Impact on Customer Satisfaction with Especial Reference to Commercial Bank of Ceylon PLC." Global Journal of Management and Business Research Volume 12 Issue 17.

[27] Ritika, T. (2013) "Porter's Generic Strategies" Journal of Business and Management" Volume 15, Issue 1. 
[28] Smith W. R. (1956), Product Differentiation and market segmentation as alternative marketing strategies, National Quarterly Publication, USA.

[29] Solomon, M., Bamossy, G. \& Askegaard, S., (1999), "Consumer behaviour - A European Perspective", New Jersey: Prentice Hall Europe.

[30] Steiger, J. H. (2007), "Understanding the limitations of global fit assessment in structural equation modeling," Personality and Individual Differences, 42 (5), 893-98.

[31] Sweeney, J. C. and Soutar, G. N. (2001) "Consumer Perceived
Value: The Development of a Multiple Item Scale". Journal of Retailing, 77, 203-220.

[32] Wedel, M \& Kamakura, W. A. (1999), "Market segmentation: Conceptual and methodological foundations". Kluwer Academic Publishers, Dordrecht/Boston/London.

[33] Wind, Y. 1978. Issues and Advances in Segmentation Research. Journal of Marketing Research. 15. (3). pp. 317-337.

[34] Yim, C. K and Kannan, P. K (1999). "Consumer Behavioral Loyalty: A Segmentation Model and Analysis". Journal of Business Research 44 (2): 75-92. 